\title{
Geographic patterns of genetic differentiation and plumage colour variation are different in the pied flycatcher (Ficedula hypoleuca)
}

\author{
PAULA K. LEHTONEN, * TONI LAAKSONEN, *, §§§ ALEKSANDR V. ARTEMYEV, †EUGEN \\ BELSKII, $\ddagger$ CHRISTIAAN BOTH, $\S$ STANISLAV BURE $\check{S},-$ ANDREY V. BUSHUEV, ${ }^{* *}$ IND RIKIS \\ KRAMS, $*$, †† JUAN MORENO, 扭 MARKO MÄGI, § ANDREAS NORD,-- JAIME POTTI,*** \\ PIERRE-ALAIN RAVUSSIN, †† P ÄIVI M. SIRKIÄ,* GLENN-PETER SÆTRE柿 and \\ CRAIG R. PRIMMER*
}

*Department of Biology, University of Turku, Turku 20014, Finland, †Institute of Biology, Karelian Research Centre, Russian Academy of Science, 185610 Petrozavodsk, Russia, ¥Institute of Plant and Animal Ecology, Russian Academy of Science, 620144 Ekaterinburg, Russia, §Centre for Ecological and Evolutionary Studies, University of Groningen, 9750 AA Haren, The Netherlands, -Laboratory of Ornithology, Palacký University, 77146 Olomouc, Czech Republic, **Department of Vertebrate Zoology, Biological Faculty, Moscow State University, 119992 Moscow, Russia, ††Institute of Systematic Biology, University of

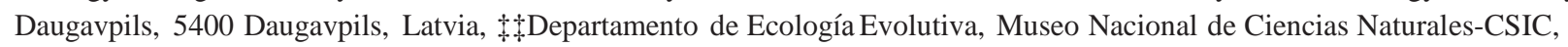
28006 Madrid, Spain, §§Department of Zoology, Institute of Ecology and Earth Sciences, University of Tartu, 51014 Tartu, Estonia, -Department of Animal Ecology, Lund University, 22362 Lund, Sweden, ***Department of Evolutionary Ecology, Estación Biológica de Doñana-CSIC, 41092 Sevilla, Spain, †††Rue du Theu, CH-1446 Baulmes, Switzerland, 䖞Centre for Ecological and Evolutionary Synthesis (CEES), Department of Biology, University of Oslo, PO Box 1066 Blindern, N-0316 Oslo, Norway

\begin{abstract}
The pied flycatcher is one of the most phenotypically variable bird species in Europe. The geographic variation in phenotypes has often been attributed to spatial variation in selection regimes that is associated with the presence or absence of the congeneric collared flycatcher. Spatial variation in phenotypes could however also be generated by spatially restricted gene flow and genetic drift. We examined the genetic population structure of pied flycatchers across the breeding range and applied the phenotypic $\mathrm{Q}_{\mathrm{ST}}$ $\left(\mathrm{P}_{\mathrm{ST}}\right)-\mathrm{F}_{\mathrm{ST}}$ approach to detect indirect signals of divergent selection on dorsal plumage colouration in pied flycatcher males. Allelic frequencies at neutral markers were found to significantly differ among populations breeding in central and southern Europe whereas northerly breeding pied flycatchers were found to be one apparently panmictic group of individuals. Pairwise differences between phenotypic $\left(\mathrm{P}_{\mathrm{ST}}\right)$ and neutral genetic distances $\left(\mathrm{F}_{\mathrm{ST}}\right)$ were positively correlated after removing the most differentiated Spanish and Swiss populations from the analysis, suggesting that genetic drift may have contributed to the observed phenotypic differentiation in some parts of the pied flycatcher breeding range. Differentiation in dorsal plumage colouration however greatly exceeded that observed at neutral genetic markers, which indicates that the observed pattern of phenotypic differentiation is unlikely to be solely maintained by restricted gene flow and genetic drift.
\end{abstract}

Keywords: colonization, genetic differentiation, microsatellites, passerine birds, phylogeography, pigmentation, $\mathrm{P}_{\mathrm{ST}}-\mathrm{F}_{\mathrm{ST}}$

Received 1 July 2009; revision received 14 August 2009; accepted 24 August 2009

Correspondence: Paula K. Lehtonen, Fax: + 358-(0)2- 333 6680; E-mail: paula.lehtonen@utu.fi

$\S \S \S$ Present address: Finnish Museum of Natural History, Helsinki, Finland 


\section{Introduction}

Geographic variation in traits with a genetic basis provides compelling evidence for spatial variation in selection regimes (Haldane 1948; Slatkin 1973). Such variation is of particular interest in highly mobile species that have few barriers to dispersal and nevertheless exhibit stark population-specific patterning in phenotypes. Apparently connected populations may however be isolated or partially isolated when maximum capacity for dispersal is not realized (e.g. Avise 1996; Piertney et al. 1998, 1999). Consequently, spatial variation in the propensity to disperse could lead to isolation or partial isolation producing variation in allele frequencies that is maintained with very little selection or even solely by genetic drift (Lande 1976; Lynch 1988; Vasemä gi 2006). Understanding the relative contributions of these deterministic (natural selection) and stochastic (random genetic drift and restricted gene flow) processes in the production and maintenance of genetic differentiation is crucial to our understanding of local adaptation and fundamentally, evolution.

Despite the recent leap in our understanding of the genetic basis of quantitative trait variation in natural populations (e.g. Mundy et al. 2004; Chenoweth \& Blows 2006; Hoekstra et al. 2006; Gratten et al. 2008), in the vast majority of cases not enough is known about the genetic details of a trait and the selective factors that influence it to be able to firmly conclude that the trait is evolving non-neutrally (Leinonen et al. 2008). Thus, one of the currently most accessible tools for examining the contribution of non-neutral evolutionary forces to quantitative trait variation is to compare differentiation at quantitative traits $\left(\mathrm{Q}_{\mathrm{ST}}\right.$ or its phenotypic analogue, $\mathrm{P}_{\mathrm{ST}}$; Spitze 1993) to differentiation at putatively neutral molecular markers ( $\mathrm{F}_{\mathrm{ST}}$; Wright 1951). The rationale behind this approach lies on the assumption that population differentiation observed in selectively neutral parts of the genome provides the null model for the extent of differentiation that results from migration and drift alone (Merilä \& Cnokrak 2001; McKay \& Latta 2002; Leinonen et al. 2008). When differentiation at these two estimators is equal $\left(\mathrm{P}_{\mathrm{ST}}=\mathrm{F}_{\mathrm{ST}}\right)$ the observed degree of differentiation at quantitative traits could have been reached solely by genetic drift (Merilä \& Cnokrak 2001; Leinonen et al. 2008). One cannot, however, firmly exclude selection as an underlying cause of variation, but merely that it is not possible to quantify the relative contributions of selection and drift (Hendry 2002; Leinonen et al. 2008). If differentiation at quantitative traits is more pronounced than that observed for selectively neutral parts of the genome $\left(\mathrm{P}_{\mathrm{ST}}>\mathrm{F}_{\mathrm{ST}}\right)$ this is suggestive of directional selection influencing the trait; when neutral marker variation is greater than that observed for quantitative traits $\left(\mathrm{P}_{\mathrm{ST}}<\mathrm{F}_{\mathrm{ST}}\right)$, balancing selection is inferred (Merilä \& Cnokrak 2001; Leinonen et al. 2008). One of the main criticisms raised concerning the $\mathrm{P}_{\mathrm{ST}}-\mathrm{F}_{\mathrm{ST}}$ approach is that the surrogate for the amount of additive genetic variance utilized $\left(\mathrm{P}_{\mathrm{ST}}\right)$, may be confounded by nongenetic (environmental or maternal) or genetic nonadditive (epistatic or dominance variance) effects when measured from free-living individuals (Pujol et al. 2008). However, as common garden and reciprocal transplant experiments are not feasible for a wide range of species and morphological traits are known to exhibit substantial additive genetic variance (Cnokrak \& Roff 1995; Merilä \& Cnokrak 2001) the methodology nevertheless provides a valuable starting point. $\mathrm{P}_{\mathrm{ST}}-\mathrm{F}_{\mathrm{ST}}$ comparisons have been increasingly utilized to detect signals of non-neutral evolution in a wide range of taxa (Spitze 1993; Lynch et al. 1999; Storz 2002; Saint-Laurent et al. 2003; Leinonen et al. 2006; Raeymaekers et al. 2007; Sæther et al. 2007).

We investigate the relative roles of selection and gene flow and genetic drift on the breeding plumage colour variation of pied flycatcher (Ficedula hypoleuca) males. Male pied flycatchers vary in their dorsal breeding plumage along a continuum ranging from a female-like brown to completely black. The frequencies of differently coloured males vary across the breeding range with brown individuals being very common in Central Europe whereas darker males increase in frequency as the distance from the Central European breeding areas increases (Røskaft et al. 1986; Lundberg \& Alatalo 1992; Huhta et al. 1997). The dorsal plumage colour of pied flycatcher males is a melanin-based (Lundberg \& Alatalo 1992) heritable (Alatalo et al. 1994) trait that has been indicated to be subjected to different selection regimes depending on the presence or absence of the dominant congeneric black-and-white collared flycatcher (Ficedula albicollis; Lundberg \& Alatalo 1992; Sætre et al. 1997). The high frequency of brown, femalelike males in the Central European areas of sympatry is suggested to stem from selection for accurate species recognition (Sætre et al. 1997) and reduced inter-specific male-male aggression (Sætre et al. 1993; Alatalo et al. 1994). When the collared flycatcher is not present, the frequency of more darkly coloured males increases and dorsal plumage colour has been suggested to be sexually selected for. The direction of the preference has not, however, been equivocally demonstrated and a female preference for both dark males (Sætre et al. 1994) and brown males (Lifjeld et al. 1997) and the absence of any obvious preference (Lundberg \& Alatalo 1992; Rätti et al. 1995; Lifjeld et al. 1998; Lehtonen et al. 2009) have been reported. 
In addition to spatial variation in dorsal plumage colouration, pied flycatchers exhibit latitudinal variation in their propensity to disperse (von Haartman 1960; Lundberg \& Alatalo 1992). Natal philopatry in central and southern Europe tends to be higher than that found in northern Europe and similarly, female return rates decrease with increasing latitude (von Haartman 1960; Lundberg \& Alatalo 1992; Sanz 2001). Latitudinal differences in dispersal propensity have been suggested to reflect latitudinal differences in the ecological characteristics of the breeding areas (Lundberg \& Alatalo 1992). Isolation or partial isolation between populations stemming from patchy forest cover (Lundberg \& Alatalo 1992) and /or altitude (Potti \& Montalvo 1991) could increase the probability of recruiting to the population of origin if no appropriate alternative breeding areas exist nearby.

In light of what is known about spatial variation in selection pressures on the dorsal plumage colouration in this species and spatial variation in the degree of population isolation stemming from habitat characteristics, our aim was to examine whether plumage colour variation in pied flycatcher males is maintained by nonneutral evolutionary forces or through restricted dispersal and random genetic drift. First, we quantify the extent of neutral genetic differentiation across the pied flycatcher breeding range. Then, we assess the extent of population differentiation in dorsal plumage colouration and compare this to the patterns of neutral genetic variation.

\section{Materials and methods}

\section{Sampling}

A total of 631 pied flycatcher males belonging to 16 different nestbox populations were caught and sampled during the breeding seasons of 1994-2008 (Fig. 1; see Table 1 for population-specific information). The dorsal colour of 576 of the males (no colour information available for the population sample from Lingen, Germany) was classified according to the Drost scale (Drost 1936; Lundberg \& Alatalo 1992). The score has seven classes, ranging from 1 (fully black head and back) to 7 (fully brown head and back) and has been used as a standard measure of flycatcher colouration for decades (Lundberg \& Alatalo 1992). A blood or feather sample was collected from each male for genetic analyses and stored at ) $20{ }^{\circ} \mathrm{C}$ or room temperature respectively.

\section{Molecular analyses}

DNA was extracted with one of two methods: a modification of the salt extraction protocol of Aljnabi \&
Martinez (1997; blood samples) or with the Nucleospin (Macherey-Nagel) extraction kit particularly suitable for extracting from small quantities of starting material (feather samples). All individuals were analysed at 19 microsatellite loci all of which have been isolated from the pied flycatcher (FhU2 described as PTC2 in Ellegren 1992; all other loci, Leder et al. 2008; Appendix S1). Markers were amplified in multiplex PCRs (QIAGEN) in groups of 4-6. PCR conditions were as outlined in Karaiskou \& Primmer (2008) and primer concentrations ranged from 0.15 to $14 \mathbf{l}$. The PCR profile was as follows: $95{ }^{\circ} \mathrm{C}$ for $15 \mathrm{~min}$ followed by 33-35 cycles at $94{ }^{\circ} \mathrm{C}$ for $30 \mathrm{~s}, 55^{\circ} \mathrm{C}$ for $90 \mathrm{~s}, 72{ }^{\circ} \mathrm{C}$ for $1 \mathrm{~min}$ followed by a final step of $60{ }^{\circ} \mathrm{C}$ for $15 \mathrm{~min}$. The forward primer of each locus was labelled with one of four fluorescent dyes (FAM, PET, NED, TET) and the reverse primer always had a GTT-tail in its 3t end to enhance the polyadenylation of the amplified fragment. The amplified fragments were divided into three panels that were electrophoresed on an ABI 3130 fragment analyser (Applied Biosciences).

\section{Data quality control and gene diversity indices}

The presence of genotyping errors arising from technical artefacts, namely null alleles or large allele dropout due to poor DNA quality was assessed using the program Micro-CHECKer (van Oosterhout et al. 2004). The genotypes of all samples and loci that were indicated to exhibit signs of either null alleles or allelic dropout were re-examined for scoring errors. Errors arising from family sampling were controlled for by examining each population sample for the presence of full-sibs with the COLONY 1.2 program (Wang 2004).

Allele frequencies, number of alleles, allelic richness, and observed and expected heterozygosities were calculated for each sample and every locus using the MICROSATellite toolkit (Park 2001) Excel add-in and Fstat 2.9.3 (Goudet 1995). The allelic richness calculation method employed by the FSTAT 2.9.3 program corrects allele number for sample size using the rarefaction method outlined in El Mousadik \& Petit (1996).

The program Genepop 3.4 (Raymond \& Rousset 1995) was utilized to test for statistically significant deviations from the Hardy-Weinberg and genotypic linkage equilibrium. A sequential Bonferroni type method [at = 1 ) (1 ) a) $1 / \mathrm{k}$; Rice 1989; Gotelli \& Ellison 2004] was employed to correct for multiple testing.

\section{Neutral genetic differentiation}

The Genepop 3.4 program was further employed to calculate a global $\mathrm{F}_{\mathrm{ST}}$ value and pairwise $\mathrm{F}_{\mathrm{ST}}$ (Weir \& Cockerham 1984) estimates for each population pair. 


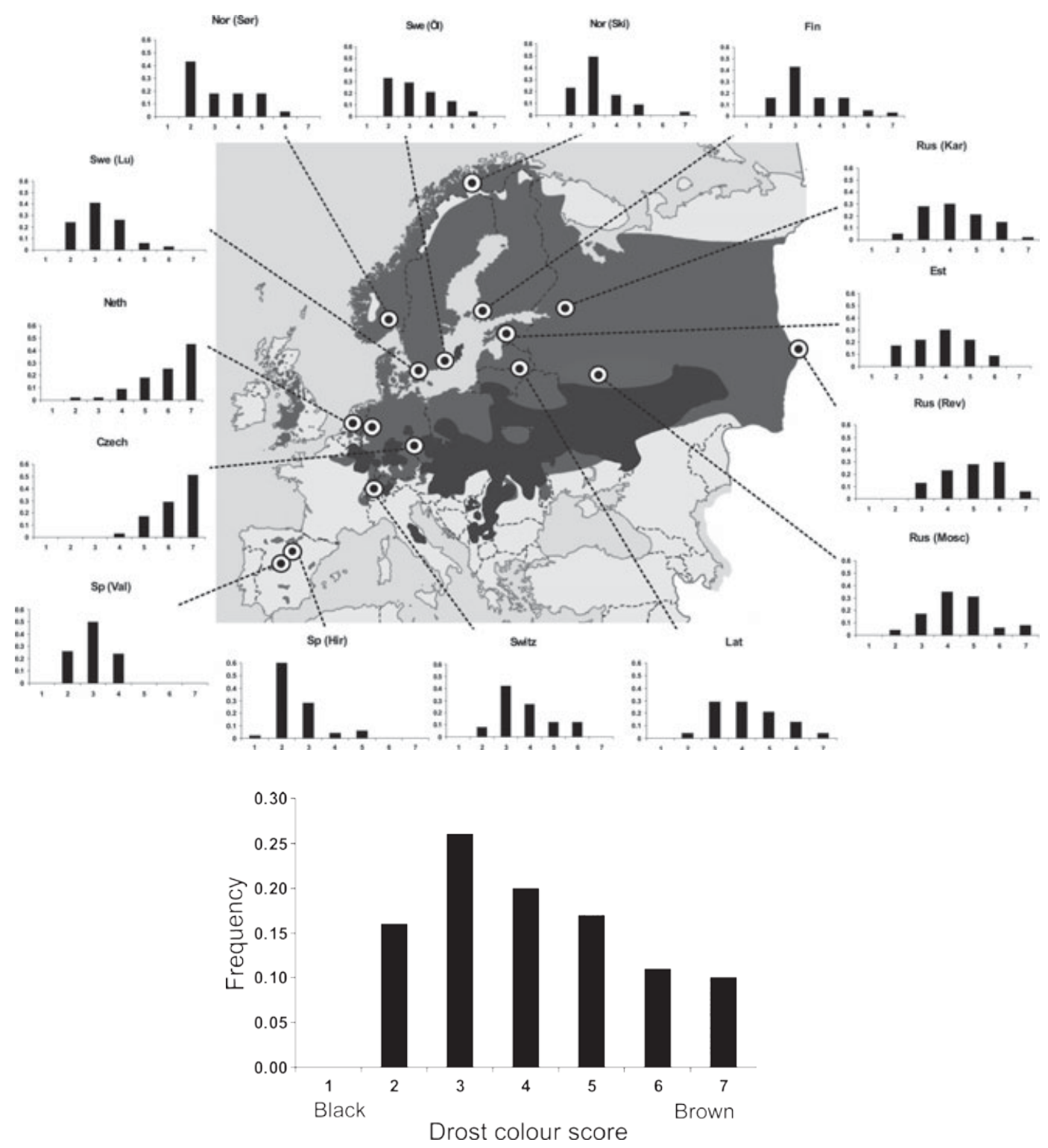

Fig. 1 A map of Europe and western Russia indicating the sampling sites and colour score frequencies of the population samples used in this study. The large histogram is drawn from the total data set. The birds are scored according to the Drost scale (Drost 1936). The darker grey patch in the centre indicates the breeding range of the collared flycatcher (which overlaps with that of the pied flycatcher for the most part) and the lighter grey area represents the breeding distribution of the pied flycatcher. Precise sampling sites and population details are listed in Table 1. No colour data was available for Lingen, Germany.

Fisher's exact test as implemented in Genepop 3.4 was used to test for differences in allelic frequency distributions between all sample pairs for every locus. Unbiased estimates were obtained with 5000 iterations (Guo \& Thompson 1992). Probability values over all loci were obtained by the Fisher method (Sokal \& Rohlf 1995). Additionally we calculated pairwise standardized $\mathrm{F}_{\mathrm{ST}}$ values $\left(G_{\mathrm{ST}}^{0}\right.$ sensu Hedrick 2005) to measure population differentiation standardized for the level of sub-population heterozygosity. However, as $F_{S T}$ and $G_{S T}^{0}$ were found to be highly correlated $(\mathrm{r}=0.99, \mathrm{P}=0.001)$ and standardized versions of $\mathrm{F}_{\mathrm{ST}}$ are not applicable to $\mathrm{P}_{\mathrm{ST}}-$ $\mathrm{F}_{\mathrm{ST}}$ comparisons (B. O’Hara, personal communication) the $\mathrm{G}_{\mathrm{ST}}^{0}$ values were not used in further analyses.

The maximum difference Monmonier's algorithm of Manni et al. (2004) as implemented in the program BARRIER 2.2 was employed to locate geographical areas associated with genetic discontinuities across the pied flycatcher breeding range. The program connects the samples according to Delauney triangulation using the sampling co-ordinates of the populations. The edges of the triangulation are then associated to a measure of 
Table 1 Population details and gene diversity statistics per population

\begin{tabular}{|c|c|c|c|c|c|c|c|c|}
\hline \multicolumn{5}{|l|}{ Population details } & \multicolumn{4}{|c|}{ Genetic diversity } \\
\hline Area & Country & Abbreviation & Co-ordinates & Year & $\mathrm{N}$ & $\mathrm{R}_{\mathrm{t}}$ & $\mathrm{H}_{\mathrm{e}}$ & Group \\
\hline Drenthe & Netherlands & Neth & $52^{\circ} 52 \mathrm{cN} 6^{\circ} 17 \mathrm{CE}$ & 2008 & 56 & 4.96 & 0.82 & S \\
\hline Jeseníky Mountains & Czech Republic & Czech & $49^{\circ} 57 \not \mathrm{N}, 17^{\circ} 09 \measuredangle \mathrm{E}$ & 1994-2002 & 34 & 4.79 & 0.79 & $\mathrm{~S}$ \\
\hline Karelia & Russia & Rus (Kar) & $60^{\circ} 46 \mathrm{c} N 32^{\circ} 48 \mathrm{tE}$ & 2008 & 62 & 4.95 & 0.82 & $\mathrm{~N}$ \\
\hline Kilingi-Nõmme & Estonia & Est & $58^{\circ} 8 \mathrm{cN} 24^{\circ} 95 \mathrm{cE}$ & 2008 & 24 & 4.99 & 0.82 & $\mathrm{~N}$ \\
\hline Kraslava & Latvia & Lat & $55^{\circ} 53 \mathrm{CN} 27^{\circ} 11 \mathrm{CE}$ & 2008 & 30 & 5.03 & 0.82 & $\mathrm{~N}$ \\
\hline Moscow region & Russia & Rus (Mosc) & $55^{\circ} 44 \mathrm{CN} 36^{\circ} 51 \mathrm{CE}$ & 2008 & 53 & 4.91 & 0.80 & $\mathrm{~N}$ \\
\hline La Hiruela & Spain & Sp (Hir) & $41^{\circ} 4 \mathrm{CN} 3^{\circ} 27 \mathrm{cW}$ & 2008 & 51 & 4.89 & 0.81 & $\mathrm{~S}$ \\
\hline Lingen* & Germany & Ger & $52^{\circ} 27 \mathrm{CN} 7^{\circ} 15 \mathrm{CE}$ & 1998-1999 & 40 & 4.82 & 0.80 & S \\
\hline Lund & Sweden & Swe (Lu) & $55^{\circ} 39 \lessdot \mathrm{N} 13^{\circ} 55 \mathrm{cE}$ & 2008 & 34 & 5.05 & 0.82 & $\mathrm{~N}$ \\
\hline Sørkedalen & Norway & Nor (Sør) & $60^{\circ} 1 \mathrm{CN} 10^{\circ} 37 \mathrm{CE}$ & $1995-2000$ & 28 & 4.99 & 0.82 & $\mathrm{~N}$ \\
\hline Skibotn & Norway & Nor (Ski) & $69^{\circ} 20 \lessdot \mathrm{cN} 20^{\circ} 44 \mathrm{CE}$ & 2007 & 35 & 4.96 & 0.81 & $\mathrm{~N}$ \\
\hline Revda & Russia & Rus (Rev) & $56^{\circ} 51 \mathrm{CN} 59^{\circ} 53 \mathrm{CE}$ & 2008 & 47 & 4.98 & 0.82 & $\mathrm{~N}$ \\
\hline Ruissalo & Finland & Fin & $60^{\circ} 26 \mathrm{CN} 22^{\circ} 10 \mathrm{CE}$ & 2005-2006 & 37 & 4.96 & 0.81 & $\mathrm{~N}$ \\
\hline Valsaín & Spain & Sp (Val) & $40^{\circ} 52 \mathrm{CN} 4^{\circ} 1 \mathrm{cW}$ & 2008 & 36 & 4.93 & 0.82 & $\mathrm{~S}$ \\
\hline Vaud & Switzerland & Switz & $46^{\circ} 50 \mathrm{CN} 6^{\circ} 42 \mathrm{CE}$ & 2008 & 26 & 4.4 & 0.76 & S \\
\hline Öland & Sweden & Swe (Öl) & $57^{\circ} 10 \mathrm{CN} 16^{\circ} 58 \mathrm{CE}$ & 2001-2004 & 24 & 4.93 & 0.81 & $\mathrm{~N}$ \\
\hline
\end{tabular}

$\mathrm{R}_{\mathrm{t}}$, allelic richness (mean allele number corrected for sample size); $\mathrm{H}_{\mathrm{e}}$, expected heterozygosity (gene diversity), Geographic group:

$\mathrm{N}$, northern; S, southern (see text).

*No colour information available.

genetic differentiation $\left(\mathrm{F}_{\mathrm{ST}} / \mathrm{h}\right.$, Weir \& Cockerham 1984). The algorithm allows the identification of areas/edges with the highest rate of genetic change. The analysis was performed with the pairwise $\mathrm{F}_{\mathrm{ST}}$ values for each of the loci individually and also with the entire data set. Only barriers supported by a minimum of 10 of the loci were retained.

To examine whether genetic differentiation could be arising from a recent population bottleneck, Wilcoxon's test for heterozygote excess as implemented in the program воTTLENECK 1.2.02 was employed (Cornuet \& Luikart 1996). During a population bottleneck there is a reduction in the number of alleles and heterozygosity, but the former is lost faster than the latter (Maruyama \& Fuerst 1985). In short, the test looks for signatures of a bottleneck in the population sample by examining the ratio of loci showing heterozygote excess to heterozygote deficiency and comparing these to values obtained from coalescent simulations given a particular mutation model. The mutation model utilized was two-phased with the frequency of stepwise mutation models set at $95 \%$ and the infinite allele model at 5\% as recommended by Piry et al. (1999).

Phenotypic differentiation at dorsal plumage colouration

Under divergent selection, divergence at phenotypic traits will be larger than that observed for neutral loci (Leinonen et al. 2008). To examine the data set for indir- ect signals of divergent selection we calculated global $\mathrm{P}_{\mathrm{ST}}$ and pairwise $\mathrm{P}_{\mathrm{ST}}$ values for all population pairs. $\mathrm{P}_{\mathrm{ST}}$ is analogous to $\mathrm{Q}_{\mathrm{ST}}$ and is utilized to quantify the amount of between population phenotypic variance in quantitative traits (Raeymaekers et al. 2007). $\mathrm{P}_{\mathrm{ST}}$ was estimated as:

$P_{\mathrm{ST}} 1 / 4 \frac{g \mathbf{r}_{\mathrm{GB}}^{2}}{g \mathbf{r}_{\mathrm{GB}}^{2} \mathbf{p} 2 \mathrm{\gamma h}^{2} \mathbf{r}_{\mathrm{GW}}^{2} \mathrm{p}} ;$

where $\mathbf{r}_{\mathrm{GB}}^{2}$ is the variance between populations, $\mathbf{r}_{\mathrm{GW}}^{2}$ is the variance within populations $g$ is the proportion of the differences among populations that is assumed to have an additive genetic basis and $\mathrm{h}^{2}$ is the proportion of differences among individuals within populations assumed to have an additive genetic basis (narrow sense heritability). As the data are purely phenotypic the calculation requires an assumption of the amount of additive genetic variance contributing to among (g) and within $\left(\mathrm{h}^{2}\right)$ population differences in plumage colouration in our sampled populations. The heritability of a trait is, in reality, a population-and environment-specific parameter. Of the 16 populations included in this study, heritability estimates were available for La Hiruela, Spain $\left(\mathrm{h}^{2}=0.6\right.$, measured from 275 families; J. Potti, unpublished data) and Karelia, Russia $\left(\mathrm{h}^{2}=0.82\right.$ measured from 81 families; A. Artemyev, unpublished data). The heritability of dorsal plumage colour in pied flycatcher males has previously been reported to be 0.76 (Oka-Terrace Biospheric Reserve, Russia; located 120 km 
south-east of the Moscow region population included in this study; Grinkov 2000) and 0.88 (Cumbria, England; Alatalo et al. 1994). Since the observed heritability for this character lies within a relatively narrow range and obtaining a population-specific heritability estimate for all of our samples was not possible, all of our calculations of $\mathrm{P}_{\mathrm{ST}}$ assume the heritability of dorsal plumage colouration to be the same for all populations. Similarly, the additive genetic proportion (g) of differences between populations is assumed to be uniform across the breeding range. To examine the influence of variable estimates of the amount of additive genetic variance on our values of phenotypic divergence, a sensitivity analysis simulating different estimates of $g$ and $h^{2}$ was performed.

The Drost scores were examined on an ordinal scale as they did not follow a normal distribution and the rate of change from one colour class to the next is not equal across classes (McCullagh \& Nelder 1989; chapter 5). A Bayesian approach (Gelman et al. 2004) was used to fit the data into the models, and the full posterior distribution of all the parameters of interest was estimated $\left(\boldsymbol{\Gamma}_{\mathrm{GB}}{ }^{2}, \mathbf{\Gamma}_{\mathrm{Gw}}{ }^{2}, \mathrm{P}_{\mathrm{ST}}\right)$. All the models were fitted using a Gibb's sampler with the winBUgs 1.4 package (Spiegelhalter et al. 2003). The prior distributions were uninformative, while the posterior distributions were obtained by running two chains (10 000 iterations after a burn-in of 1000 iterations and convergence reached), every second of the 2-10000 iterations was taken to give 2 - 5000 draws from the posterior distribution.

The confidence intervals of the $\mathrm{P}_{\mathrm{ST}}$ values were then compared to those obtained for neutral genetic differentiation $\left(\mathrm{F}_{\mathrm{ST}}\right)$. The difference was interpreted as significant when the confidence intervals of the two divergence estimators did not overlap.

The relationship between $\mathrm{P}_{\mathrm{ST}}$ and $\mathrm{F}_{\mathrm{ST}}$ was further examined with a mantel test of matrix correspondence (Mantel 1967) as implemented in Genalex v. 6 (Peakall \& Smouse 2006). In short, the test quantifies the correlation between two matrices ( $\mathrm{x}$ and $\mathrm{y}$ ) by first calculating the sum of squares for both the $\mathrm{x}$ and the $\mathrm{y}$ matrices $\left[R(x-\bar{x})^{2}\right.$ and $R(y-\bar{y})^{2}$ respectively]. From this, the sum of the cross products $\left(\mathrm{SP}_{\mathrm{xy}}\right)$ is then computed $[R(x-\bar{x})(y-\bar{y})]$ which is utilized in the calculation for the correlation between the matrices $\left(R_{x y}\right)$ using the formula $\mathrm{SP}_{\mathrm{xy}} /\left(\mathrm{SS}_{\mathrm{x}}-\mathrm{SS}_{\mathrm{y}}\right)^{0.5}$. The significance of the tests was obtained with 1000 permutations.

\section{Results}

The locus Fhy402 was found to consistently exhibit null alleles in all population samples and was thus excluded from further analyses. None of the populations or loci exhibited consistent deviations from Hardy-Weinberg expectations. The locus Fhy350 exhibited heterozygote deficiency in the Dutch population, but as no such deviation was observed in any of the other populations the locus was not excluded from the data set. All of the loci were in linkage equilibrium. The program COLONY 1.3 identified 14 fullsib pairs within the data set. One randomly chosen individual from each full sib pair was excluded from further analyses.

\section{Gene diversity indices}

The mean number of alleles per population ranged from 8.06 (Vaud, Switzerland) to 14.89 (Karelia, Russia; Table 1). Gene diversity (expected heterozygosity) values varied between 0.76 (Vaud, Switzerland) and 0.82 (Valsaín, Spain) and allelic richness ranged from 4.4 (Vaud, Switzerland) to 5.05 (Lund, Sweden; Table 1). The number of alleles per locus was between 10 (FhU2, Fhy468) and 48 (Fhy350; Appendix S1) and locus-specific heterozygosities varied between 0.56 (Fhy468) and 0.95 (Fhy228; Appendix S1)

\section{Neutral genetic differentiation}

The global $\mathrm{F}_{\mathrm{ST}}$ value was 0.01 (95\% C.I $0.007-0.014$ ) and the pairwise $\mathrm{F}_{\mathrm{ST}}$ values ranged between zero (many of the north-north pairs, Table 2) and 0.052 (Vaud, Switzerland - Valsaín, Spain; Table 2). Overall, all pairwise values including the Swiss sample or either of the Spanish samples were 10-fold larger than any of the other values (Table 2). As the two Spanish and the Swiss populations were much more differentiated and smaller than the other populations, we examined whether the higher differentiation could be stemming from a recent population bottleneck. No indication of a bottleneck was found in any of the populations.

Three areas of genetic discontinuity that were fully or partially supported by 10 or more loci were identified by the program BARRIER 2.2 (Fig. 2). The first, fully supported by 17 of the 18 loci separated the two Spanish populations from all of the other populations. The second break supported fully by nine loci and partially by all other loci separated the Swiss population from all other populations (Fig. 2). The third discontinuity, supported by 10 loci separated the Dutch and German populations from each other and the northern populations (Fig. 2).

The exact test for pairwise genic differentiation indicated that 73 of the 120 population pairs were significantly differentiated at the $5 \%$ level. Almost all of these (70/73) were pairwise comparisons where either one or both members of the pair belonged to the southern group (see Table 1 for population groupings). Similarly, the vast majority $(42 / 47)$ of the population pairs that 
Table 2 Pairwise $\mathrm{P}_{\mathrm{ST}}$ values $\left(\mathrm{h}^{2}=1\right.$; above the diagonal) and pairwise $\mathrm{F}_{\mathrm{ST}}$ values (below the diagonal) for all the populations included in the study

\begin{tabular}{|c|c|c|c|c|c|c|c|c|c|c|c|c|c|c|c|c|}
\hline & \multicolumn{6}{|c|}{ Central and southern populations } & \multicolumn{10}{|c|}{ Northern populations } \\
\hline & $\begin{array}{l}\text { Sp } \\
\text { (Hir) }\end{array}$ & $\begin{array}{l}\text { Sp } \\
\text { (Val) }\end{array}$ & Switz & Czech & Ger & Neth & Est & Fin & Lat & $\begin{array}{l}\text { Nor } \\
\text { (Ski) }\end{array}$ & $\begin{array}{l}\text { Nor } \\
\text { (Sør) }\end{array}$ & $\begin{array}{l}\text { Rus } \\
\text { (Kar) }\end{array}$ & $\begin{array}{l}\text { Rus } \\
\text { (Mosc) }\end{array}$ & $\begin{array}{l}\text { Rus } \\
\text { (Rev) }\end{array}$ & $\begin{array}{l}\text { Swe } \\
\text { (Lu) }\end{array}$ & $\begin{array}{l}\text { Swe } \\
\text { (Öl) }\end{array}$ \\
\hline \multicolumn{17}{|c|}{ Central and southern populations } \\
\hline Sp (Hir) & & 0.320 & 0.627 & 0.921 & - & 0.911 & 0.656 & 0.554 & 0.728 & 0.406 & 0.358 & 0.732 & 0.768 & 0.835 & 0.432 & 0.416 \\
\hline Sp (Val) & $0.001 *$ & & 0.346 & 0.881 & - & 0.862 & 0.341 & 0.184 & 0.477 & 0.065 & 0.063 & 0.483 & 0.560 & 0.707 & 0.078 & 0.080 \\
\hline Switz & $0.049 *$ & $0.052 *$ & & 0.811 & - & 0.774 & 0.069 & 0.082 & 0.139 & 0.206 & 0.254 & 0.130 & 0.215 & 0.458 & 0.215 & 0.204 \\
\hline Czech & $0.033^{*}$ & $0.035^{*}$ & $0.019 *$ & & - & 0.081 & 0.800 & 0.837 & 0.749 & 0.868 & 0.875 & 0.751 & 0.711 & 0.565 & 0.864 & 0.866 \\
\hline Ger & $0.024 *$ & $0.027 *$ & $0.023^{*}$ & $0.006 *$ & & - & - & - & - & - & - & - & - & - & - & - \\
\hline Neth & $0.025^{*}$ & $0.028 *$ & $0.027^{*}$ & $0.011^{*}$ & $0.004 *$ & & 0.756 & 0.810 & 0.695 & 0.847 & 0.855 & 0.698 & 0.647 & 0.462 & 0.841 & 0.855 \\
\hline \multicolumn{17}{|c|}{ Northern populations } \\
\hline Est & $0.02 *$ & $0.021 *$ & $0.023^{*}$ & $0.002 *$ & $0.009 *$ & $0.005^{*}$ & & 0.113 & 0.110 & 0.255 & 0.303 & 0.0973 & 0.170 & 0.411 & 0.229 & 0.251 \\
\hline Fin & $0.024 *$ & $0.027 *$ & $0.024 *$ & 0.002 & $0.006 *$ & $0.004 *$ & 0.002 & & 0.231 & 0.113 & 0.156 & 0.229 & 0.326 & 0.551 & 0.094 & 0.118 \\
\hline Lat & $0.019 *$ & $0.001 *$ & $0.049 *$ & 0.002 & $0.003 *$ & $0.003 *$ & 0.003 & 0.003 & & 0.231 & 0.440 & 0.046 & 0.070 & 0.267 & 0.371 & 0.388 \\
\hline Nor (Ski) & $0.024 *$ & $0.025 *$ & $0.024 *$ & 0.002 & $0.006 *$ & $0.004^{*}$ & 0.003 & 0.002 & 0.001 & & 0.067 & 0.403 & 0.490 & 0.663 & 0.074 & 0.063 \\
\hline Nor (Sør) & $0.025^{*}$ & $0.029 *$ & $0.024 *$ & $0.007 *$ & $0.007 *$ & $0.004 *$ & 0.005 & 0 & 0 & 0.001 & & 0.445 & 0.526 & 0.686 & 0.051 & 0.079 \\
\hline Rus (Kar) & $0.022 *$ & $0.024 *$ & $0.021^{*}$ & $0.004 *$ & $0.005^{*}$ & $0.008^{*}$ & 0.001 & 0.001 & 0.001 & 0 & $0.003^{*}$ & & 0.053 & 0.264 & 0.375 & 0.393 \\
\hline Rus (Mosc) & $0.025^{*}$ & $0.026 *$ & $0.019 *$ & 0.002 & $0.004 *$ & $0.009 *$ & 0.003 & 0.001 & 0.002 & 0.001 & 0.005 & 0.001 & & 0.169 & 0.465 & 0.479 \\
\hline Rus (Rev) & $0.023 *$ & $0.025 *$ & $0.024 *$ & 0.001 & $0.002 *$ & $0.007 *$ & 0 & 0.003 & 0.003 & 0 & 0.002 & $0.001 *$ & 0 & & 0.647 & 0.655 \\
\hline Swe (Lu) & $0.022 *$ & $0.024 *$ & $0.018^{*}$ & $0.004 *$ & $0.003 *$ & $0.002 *$ & 0.001 & ) 0.001 & 0.001 & 0.003 & 0 & 0 & 0.001 & ) 0.001 & & 0.064 \\
\hline Swe (Öl) & $0.023 *$ & $0.023^{*}$ & $0.018^{*}$ & $0.003 *$ & $0.006 *$ & $0.011^{*}$ & $0.004 *$ & 0.001 & 0.002 & 0.001 & 0.003 & 0 & 0.001 & 0.001 & 0.003 & \\
\hline
\end{tabular}

Significant $\mathrm{F}_{\mathrm{ST}}$ values are indicated with an asterisk $\left(^{*}\right)$. No colour data was available for the population sample from Lingen, Germany (—). See Table 1 for population abbreviations. 


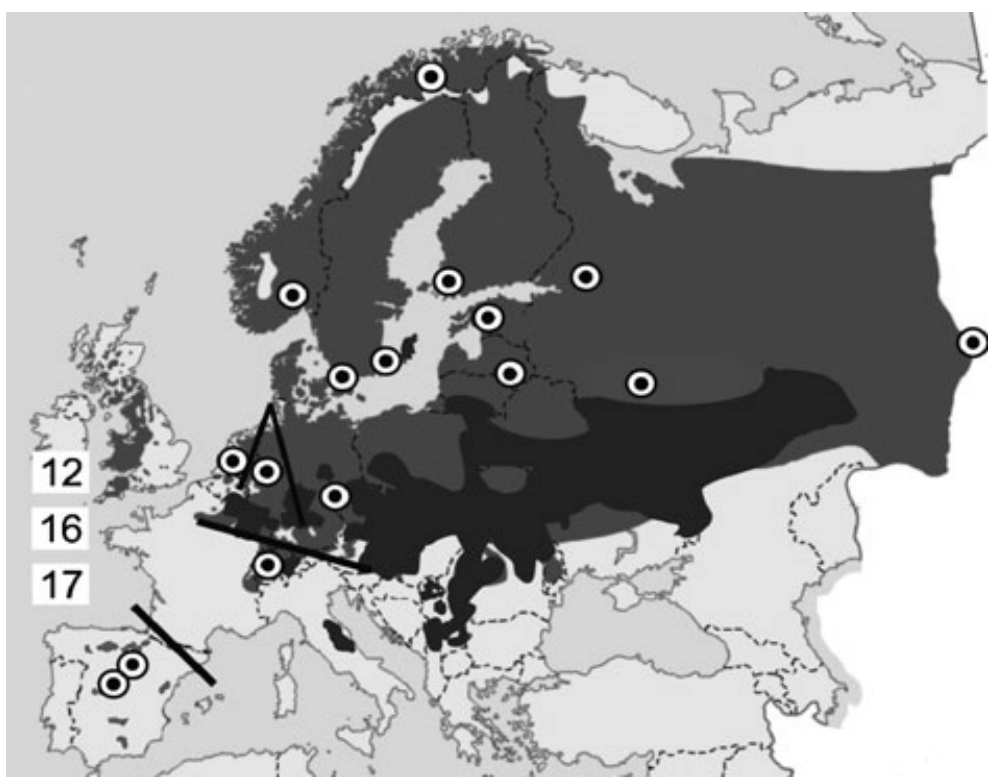

Fig. 2 Areas of genetic discontinuity identified by the program BaRrIER. The width of the barrier is proportional to the number of loci supporting it. BARRIER 1 (separating the two Spanish populations) is wholly supported by 17 loci, BARRIER 2 (separating the Swiss population from the populations more northern to it) and BARRIER 3 (separating the German and Dutch populations from each other and all other populations) are fully or partially supported by 16 and 12 loci respectively.

were undifferentiated in the pairwise comparisons were pairs of northern populations.

Phenotypic differentiation and its association with neutral genetic differentiation

The global $\mathrm{P}_{\mathrm{ST}}$ values for the different heritability estimates were $0.78\left(\mathrm{~h}^{2}\right.$ of 0.25 : $95 \%$ highest posterior density interval (HPDI) $0.74-0.82), 0.64\left(\mathrm{~h}^{2}\right.$ of $0.5 ; 95 \%$ HPDI 0.59-0.70), 0.55 ( $\mathrm{h}^{2}$ of 0.75: 95\% HPDI 0.49-0.60) $0.48\left(\mathrm{~h}^{2}\right.$ of $1: 95 \%$ HPDI $0.41-0.53$; Fig. S1). The pairwise $\mathrm{P}_{\mathrm{ST}}$ values (all calculated with $\mathrm{h}^{2}=1$ as this was the most conservative estimate and $g=1$ ) ranged from 0.05 (Karelia, Russia - Kraslava, Latvia) to 0.87 (La Hiruela, Spain - Jeseniky Mountains, Czech Republic; Table 2). The confidence intervals of the $F_{S T}$ values did not overlap with the confidence intervals of the $\mathrm{P}_{\mathrm{ST}}$ values (Fig. S1). The sensitivity analysis showed that our result was not affected by varying the additive genetic proportion of differences between (g) or within $\left(\mathrm{h}^{2}\right)$ populations (Fig. 3) No association between inter-population variation in phenotype $\left(\mathrm{P}_{\mathrm{ST}}\right)$ and neutral genetic variation $\left(\mathrm{F}_{\mathrm{ST}}\right)$ was found for the entire data set $\left(\mathrm{SP}_{\mathrm{xy}}=0.032, \mathrm{R}_{\mathrm{xy}}=0.09, \mathrm{P}=0.28\right.$; Fig. $\left.4 \mathrm{a}\right) . \mathrm{R}_{\mathrm{xy}}$ gives the correlation between the 2 matrices. The analysis was also performed without the three most differentiated populations (La Hiruela, Spain; Valsaín, Spain; Vaud, Switzerland) to enable us to examine the association at a finer scale of genetic differentiation values. Upon removing the three most highly differentiated populations, an indication of an association between genotypic and phenotypic distance was found $\left(\mathrm{SP}_{\mathrm{xy}}=0.02\right.$, $\mathrm{R}_{\mathrm{xy}}=0.37, \mathrm{P}=0.024$; Fig. 4b).

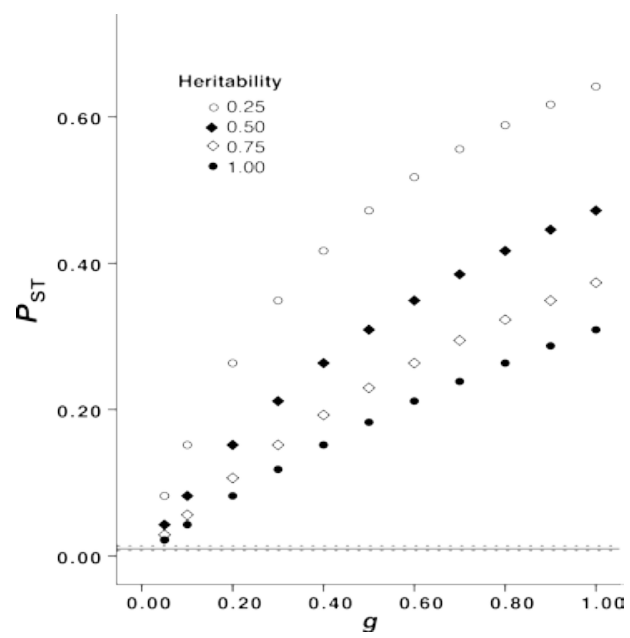

Fig. $3 \mathrm{P}_{\mathrm{ST}}$ sensitivity analysis for variable estimates of the additive genetic proportion of among population differences in dorsal plumage colour (g) calculated using four different heritability estimates $(0.25,0.5,0.7,1)$. The global $\mathrm{F}_{\mathrm{ST}}$ is shown with the solid line with the dashed lines indicating its $95 \%$ confidence intervals.

\section{Discussion}

We found a weak but significant signal of population differentiation across the pied flycatcher breeding range $\left(\mathrm{F}_{\mathrm{ST}}=0.01\right)$. More specifically, the pied flycatcher populations breeding in Northern and Eastern Europe and Russia were not differentiated from each other even over distances of thousands of kilometres. In stark contrast, populations breeding at distances of less than a hundred kilometres in Central and southern Europe 

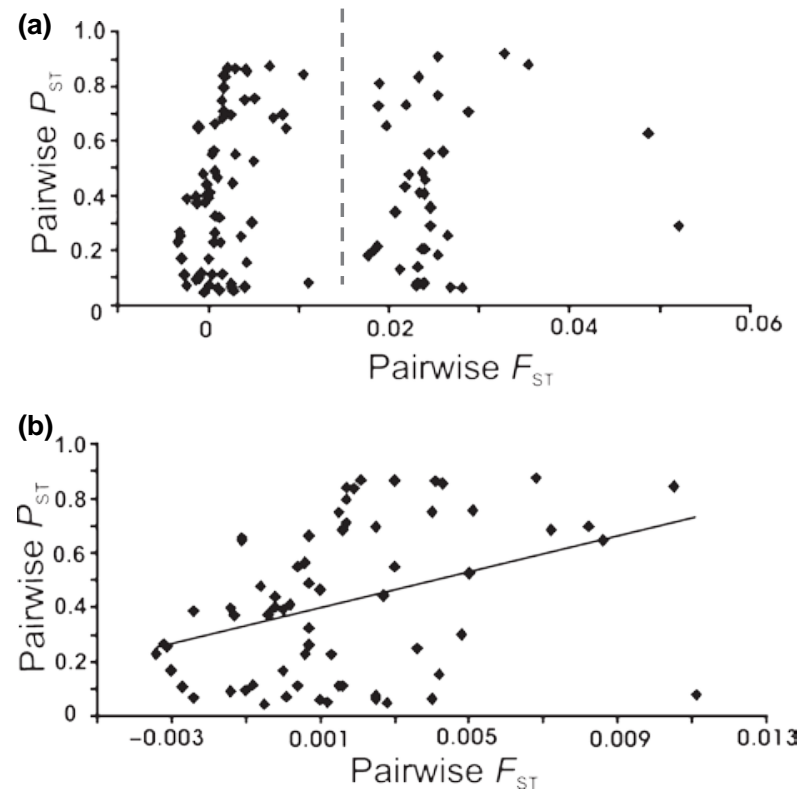

Fig. 4 Relationship between pairwise $\mathrm{P}_{\mathrm{ST}}$ values and pairwise $\mathrm{F}_{\mathrm{ST}}$ values for all populations for which colour data were available (a); and all populations except the highly differentiated Spanish and Swiss populations (b). The pairwise comparisons including the highly differentiated Spanish and Swiss populations are on the right side of the grey dashed line (a).

were found to be genetically differentiated. The comparison of the patterns of genetic differentiation with the patterns of phenotypic differentiation revealed both similarities and differences between the two. Pairwise $\mathrm{P}_{\mathrm{ST}}$ values were associated with pairwise $\mathrm{F}_{\mathrm{ST}}$ values, but only after the three most highly differentiated populations (La Hiruela, Spain; Valsaín, Spain; Vaud, Switzerland) were removed from the analysis. This is consistent with genetic drift having some role in maintaining the observed patterns of phenotypic differentiation across the continuous part of the pied flycatcher breeding range. However, as phenotypic differentiation $\left(\mathrm{P}_{\mathrm{ST}}\right)$ greatly exceeded that observed at neutral genetic markers $\left(\mathrm{F}_{\mathrm{ST}}\right)$ the trait also appears to be evolving nonneutrally.

In the following we discuss first the potential factors underlying the patterns of neutral genetic variation and then the implications of the discrepancy between neutral genetic differentiation and phenotypic differentiation.

Scenarios underlying the pattern of neutral genetic variation

Pied flycatcher populations breeding in the northern and eastern areas were found to be genetically uniform whereas those in the more southern areas were genetically differentiated, the extent of which was shown by relatively higher $\mathrm{F}_{\mathrm{ST}}$ values. The magnitude of differen- tiation is in the same range as what has previously been found in passerines using microsatellites (see, e.g. Barnett et al. 2008; Pavlacky et al. 2009). $\mathrm{F}_{\mathrm{ST}} \mathrm{S}$ reflect a combination of the amount of genetic drift and gene flow among populations. Our findings are thus indicative of extensive historical and/or contemporary gene flow between populations breeding in the northern and eastern areas.

As fossil records for birds are sparse, information on range changes during and after the last glaciations must be deduced from current day distributions together with knowledge on historical changes in the availability of suitable breeding habitat (Newton 2003). During the peak of the last glaciation, European forest cover was restricted to three areas - the Iberian, Italian and Balkan peninsulas (Newton 2003). A possible explanation for the pattern of genetic differentiation observed in our study may thus be that existing pied flycatchers originate from individuals that were separated into three different glacial refugia during the Pleistocene. If Spanish and Swiss pied flycatchers originate from the Iberian and Italian refuges respectively, and the northern and eastern birds from the Balkan refuge, the patterns of genetic differentiation seen here could be the remnants of historical isolation in separate refugia. This pattern of post-glacial range expansion is similar to that suggested for other species including the grasshopper (Chorthippus parallelus), the great crested newt (Triturus cristatus) and the black alder (Alnus glutinosa; reviewed in Hewitt 1999).

Pied flycatchers have previously been suggested to have spread across Europe and Russia starting from the Iberian glacial refugium and expanding towards the north and east from there (Lundberg \& Alatalo 1992). Fennoscandia has been suggested to have been colonized from the central parts of Europe (Haavie et al. 2000) only during the past 200 years (Lundberg \& Alatalo 1992) and if the patterns of neutral genetic variation are interpreted in light of this colonization hypothesis, the genetically uniform eastern populations appear to originate from the same source population. The homogenous population structure in the northern and eastern areas could thus also be reflecting a recent rapid range expansion to these areas (Hewitt 1999) This hypothesis, however, leaves open the question of the origin of the relatively highly differentiated Swiss pied flycatcher population. It is possible that as the Swiss population is one of the most recently founded populations included in this study ( $<50$ years ago; Ravussin et al. 2007), the traces of a founder effect may still be apparent in the population's gene pool generating the observed pattern of genetic differentiation.

The difference in the magnitude of differentiation observed in the central and southern parts of the pied 
flycatcher breeding range may in turn be stemming from a combination of historical (Spain and perhaps Switzerland) and more recent (Central Europe) isolation. Pied flycatchers in Spain are patchily distributed at high altitudes and separated from the continental populations by the Pyrenees (Fig. 1). These factors are likely to lead to the populations being smaller and historically more isolated than most of the other populations included in this study. Spanish pied flycatchers have in fact been suggested to be a separate subspecies (Lundberg \& Alatalo 1992) and previous analyses examining the genetic differentiation of Spanish pied flycatchers have produced results similar to ours (Haavie et al. 2000). Like the Spanish populations, the relatively highly genetically differentiated Swiss pied flycatchers breed at higher altitudes than most of the other populations examined here. This could similarly lead to the partial isolation of this population and subsequent genetic differentiation but due to the above-mentioned young age of the Swiss population it is not clear whether their relatively higher genetic differentiation is a signal of historical isolation or recent colonization.

In addition to isolation-by-altitude, the observed patterns of genetic differentiation may be generated by other factors influencing contemporary gene flow between the populations. The anthropogenic effect on habitat fragmentation in Central Europe may have led to recent partial isolation of these populations, generating the patterns of genetic differentiation observed in this area. Variation in habitat fragmentation across the breeding range has also been suggested to underlie latitudinal variation in natal dispersal/home-site fidelity in pied flycatchers (Lundberg \& Alatalo 1992). Interestingly, estimates of the recruitment rates (measured as the percentage of individuals banded as nestlings that return to their natal site to breed) of these populations appear to be associated with the extent of genetic divergence between them. The most highly differentiated Spanish and Swiss populations are estimated to have the highest recruitment rates (La Hiruela 14\%, Valsaín $7 \%$, Switzerland 13\%) followed by the Czech (5.2\%) and the Dutch (3.5-6\%) populations. The estimated recruitment rates for the northern and eastern populations vary from less than $1 \%$ to $2.4 \%$. However, as each of the populations has been monitored at varying intensities over varying periods of time, performing a formal test for an association between recruitment rates and genetic differentiation was not possible.

\section{Phenotypic versus neutral genetic differentiation}

Phenotypic differentiation was found to greatly exceed neutral genetic differentiation in the pied flycatcher populations examined in this study. Patterns like these are generally interpreted as an indirect signal of divergent selection on the measured trait (Merilä \& Cnokrak 2001; Leinonen et al. 2008). Such a pattern is commonly found in comparisons of neutral genetic differentiation and morphological differentiation between populations or subspecies of birds (e.g. Seutin et al. 1995; Greenberg et al. 1998; Questiau et al. 1998; Bensch et al. 1999; Chan \& Arcese 2003; Nicholls et al. 2006). The effect of drift cannot, however, be completely ruled out in our study as neutral genetic variation was found to be associated with phenotypic variation when the three most differentiated populations were excluded from the analysis. Nevertheless, based on the low overall levels of neutral genetic differentiation, it seems reasonable to conclude that geographic variation in plumage colouration in pied flycatchers is unlikely to be solely maintained by restricted gene flow and subsequent drift. If phenotypically differentiated populations are indeed differentially adapted to the local conditions, an 'unadapted' immigrant may be less likely to contribute to the local gene pool (Nosil et al. 2005; Postma \& van Noordwijk 2005), but this may not be evident from the patterns of neutral genetic variation. It seems plausible that there is selection against the collared flycatcher resembling black males that immigrate into the Central European populations. Clutches produced by pairs where one member is a hybrid exhibit substantially reduced hatching success (Alatalo et al. 1990; Sætre et al. 1999) and indeed, females in the Central European populations have experimentally been shown to prefer brown males over black males (Sætre et al. 1997).

It is noteworthy that we measured colouration from free-living individuals, whose dorsal plumage colour is not purely the product of additive genetic effects, but may also be affected by environmental and nonadditive genetic effects (Merilä \& Cnokrak 2001; Pujol et al. 2008). Although melanin-based plumage colouration is generally thought to be a genetically determined trait (Alatalo et al. 1994; Roulin \& Dijkstra 2003) melaninbased ornaments have also been found to be influenced by nongenetic factors such as calcium enrichment of the diet (McGraw 2007) and environmental pollutants (Dauwe \& Eens 2008) in some species. Pied flycatcher males moult into their breeding plumage on the wintering grounds in Africa before initiating their migration to Europe (Lundberg \& Alatalo 1992). Not much is currently known about the amount of environmental variation the birds are exposed to before and during the moult and the way in which the populations are distributed with respect to each other on the wintering grounds. Consequently, we are unable to quantify the extent to which environmental factors may have influenced the dorsal plumage colouration of the birds included in this study. It would seem unlikely however 
that the high heritability estimates we observe throughout the breeding range would be the outcome of sons consistently being exposed to the very conditions their fathers were exposed to on the wintering grounds during a different year.

Also, in addition to the proportion of additive genetic variance within populations, we do not have the means to precisely quantify the manner in which phenotypic variation among populations is partitioned into genetic and environmental components. Again, however it would seem unlikely that the huge variation in colour score distributions among populations would be stemming from consistent differences of corresponding magnitude in wintering conditions. Furthermore, our sensitivity analysis examining the influence of varying assumptions of g showed that our results are not highly sensitive to variation in this parameter. Thus we feel confident that our interpretations of the results are not affected to any substantial degree by the potential influence of environmental conditions on estimates of phenotypic variation.

\section{Conclusions}

In conclusion, we found plumage colour variation in pied flycatchers to exhibit indirect signals of non-neutral evolution. Populations breeding in Central and southern Europe were found to be genetically differentiated, whereas northern and eastern populations appear to be one panmictic group of individuals. The results generally agree with the ideas of gradual increase in population differentiation from habitats of high connectivity to more fragmented areas and from recently isolated populations to ones subjected to historical isolation. These patterns of neutral genetic divergence were however different and substantially less pronounced than the patterns of differentiation for dorsal plumage colouration observed in pied flycatcher males. Despite the confounding factors acknowledged to potentially affect $\mathrm{P}_{\mathrm{ST}}$ estimation, $\mathrm{P}_{\mathrm{ST}}-\mathrm{F}_{\mathrm{ST}}$ comparisons nevertheless provide a valuable first step in studies aiming to detect traits influenced by divergent selection. Neutral genetic markers do not, however - by definition - bear the imprint of selection. An interesting next step in the quest to quantify the influence of selection on dorsal plumage colouration in pied flycatcher males would be to examine population differentiation at portions of the genome that may be expected to be more directly involved in plumage colouration such as various pigmentation genes.

\section{Acknowledgements}

This study was funded by the Biological Interactions Graduate School (PKL), the Centre of Excellence in Evolutionary
Genetics and Physiology (CRP \& PKL) and the Emil Aaltonen Foundation (TL). Sample collections in different populations were funded by the Estonian Science Foundation (Grant No. 7476), the Estonian Ministry of Education and Science (SF0180004s09), the European Union through the European Regional Development Fund (Center of Excellence FIBIR) and the GACR (the Czech Republic). Additionally, the study was funded by the Scientific-Educational Centres (EB; contract 02.740.11.0279; Russia), the Dirección General de Investigación (JM; project CGL2007-61251). and JP was funded during writing by project CGL2006-07481/BOS. We thank Tuomas Leinonen for assistance with $\mathrm{P}_{\mathrm{ST}}$ calculations and Bob O'Hara for statistical advice. We also thank Stein Are Sæther for valuable discussion and help with the sensitivity analyses. The manuscript was much improved by the comments of two anonymous reviewers.

\section{References}

Alatalo RV, Eriksson D, Gustafsson L, Lundberg A (1990) Hybridization between pied and collared flycatchers - sexual selection and speciation theory. Journal of Evolutionary Biology, 3, 375-389.

Alatalo RV, Gustafsson L, Lundberg A (1994) Male coloration and species recognition in sympatric flycatchers. Proceedings of the Royal Society of London, Series B: Biological Sciences, 256, 113-118.

Aljnabi SM, Martinez I (1997) Universal and rapid saltextraction of high quality genomic DNA for PCR-based techniques. Nucleic Acids Research, 25, 4629-4693.

Avise JC (1996) Three fundamental contributions of molecular genetics to avian ecology and evolution. Ibis, 138, 16-25.

Barnett JR, Ruiz-Gutierrez V, Coulon A, Lovette IJ (2008) Weak genetic structuring indicates ongoing gene flow across White-ruffed Manakin (Corapipo altera) populations in a highly fragmented Costa Rica landscape. Conservation Genetics, 9, 1403-1412.

Bensch S, Andersson T, Akesson S (1999) Morphological and molecular variation across a migratory divide in Willow warblers Phylloscopus trochilus. Evolution, 53, 1925-1935.

Chan Y, Arcese P (2003) Morphological and microsatellite differentiation in Melospiza melodia (Aves) at a microgeographic scale. Journal of Evolutionary Biology, 16, 939-947.

Chenoweth SF, Blows MW (2006) Dissecting the complex genetic basis of mate choice. Nature Reviews Genetics, 7, 681692.

Cnokrak P, Roff DA (1995) Dominance variance: associations with selection and fitness. Heredity, 75, 530-540.

Cornuet JM, Luikart G (1996) Description and power analysis of two tests for detecting recent population bottlenecks from allele frequency data. Genetics, 144, 2001-2014.

Dauwe T, Eens M (2008) Melanin- and carotenoid-dependent signals of great tits (Parus major) relate differently to metal pollution. Naturwissenschaftern, 95, 969-973.

Drost R (1936) Über das Brutkleid männlicher Trauerfliegenfä nger, Muscicapa hypoleuca. Vogelzug, 6, 179-186.

El Mousadik A, Petit RJ (1996) High levels of genetic differentiation for allelic richness among populations of the 
argan tree [Argania spinosa (L.) Skeels] endemic to Morocco. Theoretical and Applied Genetics, 92, 832-839.

Ellegren H (1992) Polymerase chain reaction (PCR) analysis of microsatellites - a new approach to studies of genetic relationships in birds. Auk, 109, 886-895.

Gelman AJ, Carlin JB, Stem HS, Rubin D (2004) Bayesian Data Analysis, 2nd edn. Chapman \& Hall, London.

Gotelli NJ, Ellison AM (2004) A Primer of Ecological Statistics. Sinauer Associates Inc., Sunderland, USA.

Goudet J (1995) FSTAT (vers. 1.2): a computer program to calculate F-statistics. Journal of Heredity, 86, 485-486.

Gratten J, Wilson AJ, McRae AF et al. (2008) A localized negative genetic correlation constrains microevolution of coat colour in wild sheep. Science, 319, 318-320.

Greenberg R, Cordero PJ, Droege S, Fleischer RC (1998) Morphological adaptation with no mitochondrial DNA differentiation in the coastal plain swamp sparrow. The Auk, 115, 706-712.

Grinkov VG (2000) Conditions of stable maintenance of phenotypic population structure in case of breeding plumage colour variation in Pied Flycatcher (Ficedula hypoleuca, Pallas) males. PhD Thesis, Moscow State University, Moscow, Russia, pp. 132 (in Russian).

Guo SW, Thompson EA (1992) Performing the exact test of Hardy-Weinberg proportion for multiple alleles. Biometrics, 48, 361-372.

von Haartman L (1960) The Ortstreu of the Pied Flycatcher. Proceedings of the XIIth International Ornithological Congress, 266-273, Tilgmann, Helsinki.

Haavie J, Sætre G-P, Moum T (2000) Discrepancies in population differentiation at microsatellites, mitochondrial DNA and plumage colour in the pied flycatcher - inferring evolutionary processes. Molecular Ecology, 9, 1137-1148.

Haldane JBS (1948) The theory of a cline. Journal of Genetics, 48, 277-283.

Hedrick PW (2005) A standardized genetic differentiation measure. Evolution, 59, 1633-1638.

Hendry AP (2002) QST > = , < FST? Trends in Ecology and Evolution, 17, 502.

Hewitt GM (1999) Post-glacial re-colonization of European biota. Biological Journal of the Linnean Society, 68, 87-112.

Hoekstra HE, Hirschmann RJ, Bundey RA, Insel PA, Crossland JP (2006) A single amino acid mutation contributes to adaptive beach mouse colour pattern. Science, 313, 101-104.

Huhta E, Siikamä ki P, Jokimä ki J (1997) Small scale geographical variation in plumage colour of pied flycatcher males. Journal of Avian Biology, 28, 92-94.

Karaiskou N, Primmer CR (2008) PCR-multiplexing for maximising genetic analyses with limited DNA: an example in the collared flycatcher, Ficedula albicollis. Annales Zoologici Fennici, 45, 478-482.

Lande R (1976) Natural selection and random genetic drift in phenotypic evolution. Evolution, 30, 314-334.

Leder EH, Karaiskou N, Primmer CR (2008) Seventy new microsatellites for the pied flycatcher Ficedula hypoleuca and amplification in other passerine birds. Molecular Ecology Resources, 8, 874-880.

Lehtonen PK, Primmer CR, Laaksonen T (2009) Different traits affect gain of extrapair paternity and loss of paternity in the pied flycatcher (Ficedula hypoleuca). Animal Behaviour, 77, 1103-1110.
Leinonen T, Cano JM, Mä kinen H, Merilä J (2006) Contrasting patterns of body shape and neutral genetic divergence in marine and lake populations of threespine sticklebacks Gasterosteus aculeatus. Journal of Evolutionary Biology, 19, 18031812.

Leinonen T, O’Hara RB, Cano JM, Merilä J (2008) Comparative studies of quantitative trait and neutral marker divergence: a meta-analysis. Journal of Evolutionary Biology, 21, 1-17.

Lifjeld JT, Slagsvold T, Dale S, Ellegren H (1997) A sexually selected paradox in the pied flycatcher: attractive males are cuckolded. The Auk, 114, 112-115.

Lifjeld JT, Slagsvold T, Ellegren H (1998) Experimentally reduced paternity affects paternal effort and reproductive success in pied flycatchers. Animal Behaviour, 55, 319-329.

Lundberg A, Alatalo RV (1992) The Pied Flycatcher. Poyser, London.

Lynch M (1988) The divergence of neutral quantitative characters among partially isolated populations. Evolution, 42, 455-466.

Lynch M, Pfrender M, Spitze K et al. (1999) The quantitative and molecular genetic architecture of a subdivided species. Evolution, 53, 100-110.

Manni F, Guerard E, Heyer E (2004) Geographic patterns of (genetic, morphologic, linguistic) variation: how barriers can be detected using Monmonier's algorithm. Human Biology, 76, 173-190.

Mantel N (1967) Detection of disease clustering and a generalized regression approach. Cancer Research, 27, 209220.

Maruyama T, Fuerst PA (1985) Population bottlenecks and non-equilibrium models in population genetics. II. Number of alleles in a small population that was formed by a recent bottleneck. Genetics, 111, 675-689.

McCullagh P, Nelder JA (1989) Generalized Linear Models, 2nd edn. Chapman and Hall, London.

McGraw KJ (2007) Dietary mineral content influences the expression of melanin-based ornamental coloration. Behavioral Ecology, 18, 137-142.

McKay JK, Latta RG (2002) Adaptive population divergence: markers, $\mathrm{Q}_{\mathrm{TL}}$ and traits. Trends in Ecology and Evolution, 17, 285-291.

Merilä J, Cnokrak P (2001) Comparison of genetic differentiation at marker loci and quantitative traits. Journal of Evolutionary Biology, 14, 892-903.

Mundy NI, Badcock NS, Hart T, Scribner K, Janssen K, Nadeau NJ (2004) Conserved genetic basis of a quantitative plumage trait involved in mate choice. Science, 303, 18701873.

Newton I (2003) The Speciation and Biogeography of Birds. Academic Press, London.

Nicholls JA, Austin JJ, Mortiz C, Goldizen AW (2006) Genetic population structure and call variation in a passerine bird, the satin bowerbird, Plitonorhynchus violaceus. Evolution, 60, 1279-1290.

Nosil P, Vines TH, Funk DJ (2005) Reproductive isolation caused by natural selection against immigrants from divergent habitats. Evolution, 59, 705-719.

van Oosterhout CV, Hutchinson WF, Willis DPM (2004) MICROCHECKER: software for identifying and correcting genotyping errors in microsatellite data. Molecular Ecology Notes, 4, 535538. 
Park SDE (2001) Trypanotolerance in West African cattle and the population genetic effects of selection. PhD Thesis, University of Dublin, Dublin.

Pavlacky DC, Goldizen AW, Prentis PJ, Nicholls JA, Lowe AJ (2009) A landscape genetics approach for quantifying the relative influence of historic and contemporary habitat heterogeneity on the genetic connectivity of a rainforest bird. Molecular Ecology, 18, 2945-2960.

Peakall R, Smouse PE (2006) Genalex 6: genetic analysis in Excel. Population genetic software for teaching and research. Molecular Ecology Notes, 6, 288-295.

Piertney SB, MacColl ADC, Bacon PJ, Dallas JF (1998) Local genetic structure in red grouse (Lagopus lagopus scoticus): evidence from microsatellite DNA markers. Molecular Ecology, 7, 1645-1654.

Piertney SB, MacColl AD, Lambin X, Moss R, Dallas JF (1999) Spatial distribution of genetic relatedness in a moorland population of red grouse (Lagopus lagopus scoticus). Biological Journal of the Linnean Society, 68, 317-331.

Piry S, Luikart G, Cornuet J-M (1999) BottlenecK: A computer program for detecting recent reductions in the effective population size using allele frequency data. Journal of Heredity, 90, 502-503.

Postma E, van Noordwijk AJ (2005) Gene flow maintains a large clutch size at a small spatial scale. Nature, 433, 65-68.

Potti J, Montalvo S (1991) Return rate, age at first breeding and natal dispersal of pied flycatchers Ficedula hypoleuca in Central Spain. Ardea, 79, 419-428.

Pujol B, Wilson AJ, Ross RIC, Pannell R (2008) Are $\mathrm{Q}_{\mathrm{ST}}-\mathrm{F}_{\mathrm{ST}}$ comparisons for natural populations meaningful? Molecular Ecology, 17, 4782-4785.

Questiau S, Eybert M-C, Gaginskaya AR, Gielly L, Taberlet P (1998) Recent divergence between two morphologically differentiated subspecies of bluethroat (Aves: Muscicapidae: Luscinia svecica) inferred from mitochondrial DNA sequence variation. Molecular Ecology, 7, 239-245.

Raeymaekers JAM, van Houdt JKJ, Larmuseau MHD, Geldof S, Volckaert FAM (2007) Divergent selection as revealed by $\mathrm{P}_{\mathrm{ST}}$ and $\mathrm{Q}_{\mathrm{TL}}$-based $\mathrm{F}_{\mathrm{ST}}$ in three-spined stickleback (Gasterosteus aculeatus) populations along a coastal-inland gradient. Molecular Ecology, 16, 891-905.

Rätti O, Hovi M, Lundberg A, Tegelströ $\mathrm{m} \mathrm{H}$, Alatalo RV (1995) Extra-pair paternity and male characteristics in the pied flycatcher. Behavioral Ecology and Sociobiology, 37, 419425.

Ravussin P-A, Arrigo D, Schaub M, Roulin A (2007) Succès de la reproduction et taux de survie du Gobemouche noir Ficedula hypoleuca dans l'ouest de la Suisse, en marge de son aire de répartition. Nos Oiseaux, 54, 29-40.

Raymond M, Rousset F (1995) Genepop (version 1.2): population genetics software for exact tests and ecumenism. Journal of Heredity, 86, 248-249.

Rice WR (1989) Analyzing tables of statistical tests. Evolution, 43, 223-225.

Røskaft E, Järvi T, Nyholm NE, Virolainen M, Winkel W, Zang H (1986) Geographic variation in secondary sexual plumage characteristics of the male pied flycatcher. Ornis Scandinavica, 17, 293-298.

Roulin A, Dijkstra C (2003) Genetic and environmental components of variation in eumelanin and phaeomelanin sex-traits in the barn owl. Heredity, 90, 359-364.
Sæther SA, Fiske P, Kålås JA et al. (2007) Inferring local adaptation from $\mathrm{Q}_{\mathrm{ST}}-\mathrm{F}_{\mathrm{ST}}$ comparisons: neutral genetic and quantitative trait variation in European populations of great snipe. Journal of Evolutionary Biology, 20, 1563-1576.

Sætre G-P, Král M, Bícik V (1993) Experimental evidence for interspecific female mimicry in sympatric Ficedula flycatchers. Evolution, 47, 939-945.

Sætre G-P, Dale S, Slagsvold T (1994) Female pied flycatchers prefer brightly coloured males. Animal Behaviour, 48, 14071416.

Sætre G-P, Moum T, Bures S, Král M, Adamjan M, Moreno J (1997) A sexually selected character displacement in flycatchers reinforces premating isolation. Nature, 387, 589592.

Sætre G-P, Král M, Bures S, Ims RA (1999) Dynamics of a clinal hybrid zone and a comparison with island hybrid zones of flycatchers (Ficedula hypoleuca and F. albicollis). Journal of Zoology, 247, 53-64.

Saint-Laurent R, Legault M, Bernatchez L (2003) Divergent selection maintains adaptive differentiation despite high gene flow between sympatric rainbow smelt ecotypes (Osmerus mordax Mitchill). Molecular Ecology, 12, 315-330.

Sanz JJ (2001) Latitudinal variation in female local return rate in the philopatric pied flycatcher (Ficedula hypoleuca). The Auk, 118, 539-543.

Seutin G, Ratcliffe LM, Boag PT (1995) Mitochondrial DNA homogeneity in the phenotypically diverse redpoll finch complex (aves: Carduelinae: Carduelis flammea-hornemanni). Evolution, 49, 962-973.

Slatkin M (1973) Gene flow and selection in a cline. Genetics, 75, 733-756.

Sokal RR, Rohlf FJ (1995) Biometry, 2nd edn. W.H. Freeman \& Cie, New York, NY.

Spiegelhalter DJ, Thomas A, Best NG, Lunn D (2003) WinBUGS Version 1.4. User Manual. MRC Biostatistics Unit, Cambridge, UK.

Spitze K (1993) Population structure in Daphnia obtusa: quantitative genetic and allozymic variation. Genetics, 135, 367-374.

Storz J (2002) Contrasting patterns of divergence in quantitative traits and neutral DNA markers: analysis of clinal variation. Molecular Ecology, 11, 2537-2551.

Vasemä gi A (2006) The adaptive hypothesis of clinal variation revisited: single-locus clines as a result of spatially restricted gene flow. Genetics, 173, 2411-2414.

Wang J (2004) Sibship reconstruction from genetic data with typing errors. Genetics, 166, 1963-1979.

Weir BS, Cockerham CC (1984) Estimating F-statistics for the analysis of population structure. Evolution, 38, 13581370.

Wright S (1951) The genetical structure of populations. Annals of Eugenics, 15, 323-354.

This paper is part of P.K.L.'s PhD thesis which aims to understand the molecular mechanisms and evolutionary significance of plumage colour variation in pied flycatchers. The paper brings together European researchers with a common interest in understanding various aspects of pied flycatcher biology. 


\section{Supporting information}

Additional supporting information may be found in the online version of this article.

Appendix S1. Diversity statistics by locus.

Fig. S1. Global $\mathrm{P}_{\mathrm{ST}}$ values calculated with the four different heritability estimates $(0.25,0.5,0.75$ and 1$)$, the global $F_{\mathrm{ST}}$ value. The error bars indicate the 95\% HPDIs $\left(\mathrm{P}_{\mathrm{ST}}\right)$ and 95\% confidence intervals $\left(\mathrm{F}_{\mathrm{ST}}\right)$.

Please note: Wiley-Blackwell are not responsible for the content or functionality of any supporting information supplied by the authors. Any queries (other than missing material) should be directed to the corresponding author for the article. 